\title{
Limitation of Near Infrared Spectroscopy Cerebral Oximetry in Predicting Neurologic Intolerance during Carotid Artery Stenting with Proximal Protection
}

\author{
Kanchan Bilgi ${ }^{1} \quad$ Rajeeb K. Mishra ${ }^{1} \quad$ Radhakrishnan M \\ ${ }^{1}$ Department of Neuroanesthesia and Neurocritical Care, National \\ Institute of Mental Health and Neurosciences (NIMHANS), \\ Bengaluru, Karnataka, India \\ 2Department of Neuroimaging and Interventional Radiology, \\ National Institute of Mental Health and Neurosciences (NIMHANS), \\ Bengaluru, Karnataka, India
}

J Neuroanaesthesiol Crit Care:2021;8:77-78

\author{
Address for correspondence Kanchan Bilgi, MBBS, MD, DNB, \\ Department of Neuroanesthesia and Neurocritical Care, Faculty \\ Building, Third Floor, National Institute of Mental Health and \\ Neurosciences, Hosur Road, Bengaluru 560029, Karnataka, India \\ (e-mail: kanchanbilgi@gmail.com).
}

Proximal balloon occlusion prior to carotid artery stenting is considered a relatively safe practice during endovascular treatment of carotid artery stenosis. Transient neurological deterioration affecting the ipsilateral hemisphere is seen soon after balloon inflation, when placed proximal to the stenotic segment. ${ }^{1}$ This occurs in cases of bilateral carotid disease due to insufficient collateral blood flow from the contralateral side. $^{2}$ Near-infrared spectroscopy cerebral oximetry (NIRS) is a valuable tool in detecting hypoperfusion-induced cerebral tissue desaturation $\left(\mathrm{rSO}_{2}\right)$ during these procedures. This helps the interventional radiologist to deflate the balloon at the earliest to reestablish the cerebral blood flow. ${ }^{3}$

We present the case of a 63-year-old male patient who presented with recurrent transient ischemic attacks in the form of slurred speech and right upper and lower limbs weakness. Informed consent was taken from the patient prior to publishing this report. Magnetic resonance imaging revealed 90 and $40 \%$ stenosis of the left and right carotid arteries, respectively. The patient was on telmisartan $40 \mathrm{mg}$ for hypertension, which was omitted for 2 days prior to the procedure. Preprocedure electrocardiogram (ECG) was normal and echocardiography showed normal systolic function and grade I diastolic dysfunction. He was prescribed tablets aspirin $150 \mathrm{mg}$ and clopidogrel $75 \mathrm{mg}$ daily for 5 days prior to left carotid artery stenting, scheduled under monitored anesthesia care. Baseline $\mathrm{rSO}_{2}$ recorded bi-frontally were $63 \%$ on the affected side (left) and $62 \%$ on the contralateral side, which remained unchanged after $\mathrm{O}_{2}$ supplementation via facemask. ECG, pulse oximetry, end-tidal carbon dioxide, and noninvasive blood pressure were monitored throughout the procedure. Fentanyl $50 \mu \mathrm{g}$ was administered during femoral artery puncture and frequent neurological examination was performed during the procedure. Angiography revealed almost $80 \%$ stenosis of the contralateral internal carotid artery, which was underestimated on the MRI ( - Fig. 1). Faint opacification of the left anterior cerebral artery was seen after contrast injection via right internal carotid artery, suggestive of minimal collateral flow. Nimodipine $2 \mathrm{mg}$ was prophylactically injected slowly intra-arterially prior to balloon inflation into the left common carotid artery by the radiologist. The blood pressure was maintained with boluses of mephentermine.

The patient was cooperative until the balloon was inflated proximal to the stenotic segment, when he suddenly developed restlessness and aphasia. Simultaneously, progressively increasing ST segment depression up to $-2.3 \mathrm{~mm}$ was noted, raising the possibility of myocardial ischemia. There was a concomitant fall in mean arterial pressure from 178/69 (mean 96) $\mathrm{mm} \mathrm{Hg}$ to 124/38 (mean 59) $\mathrm{mm} \mathrm{Hg}$. The balloon was deflated immediately. The patient soon developed contralateral hemiplegia. As the blood pressure did not respond to intravenous mephentermine boluses, phenylephrine infusion was started to keep the mean blood pressure of at least $65 \mathrm{~mm} \mathrm{Hg}$. In the meantime, dexmedetomidine infusion was started to control patient's restlessness as the heart rate was stable and frequent neurological examination was required. In spite of these hemodynamic and neurological changes, the $\mathrm{rSO}_{2}$ remained stable at above $60 \%$ throughout the event. The hemiplegia and aphasia started resolving after approximately 15 minutes after the event. A distal embolic protection device was then deployed and the stent was placed directly over the stenotic segment and a balloon was inflated within the stent lumen. No significant hemodynamic changes were noted at this time. The ST segment changes gradually resolved over
Published online

October 21, 2020
DOI https://doi.org/

$10.1055 / \mathrm{s}-0039-1697219$

ISSN 2348-0548.
(C2020. Indian Society of Neuroanaesthesiology and Critical Care. This is an open access article published by Thieme under the terms of the Creative Commons Attribution-NonDerivative-NonCommercial-License, permitting copying and reproduction so long as the original work is given appropriate credit. Contents may not be used for commercial purposes, or adapted, remixed, transformed or built upon. (https://creativecommons.org/licenses/by-nc-nd/4.0/).

Thieme Medical and Scientific Publishers Pvt. Ltd. A-12, 2nd Floor, Sector 2, Noida-201301 UP, India 


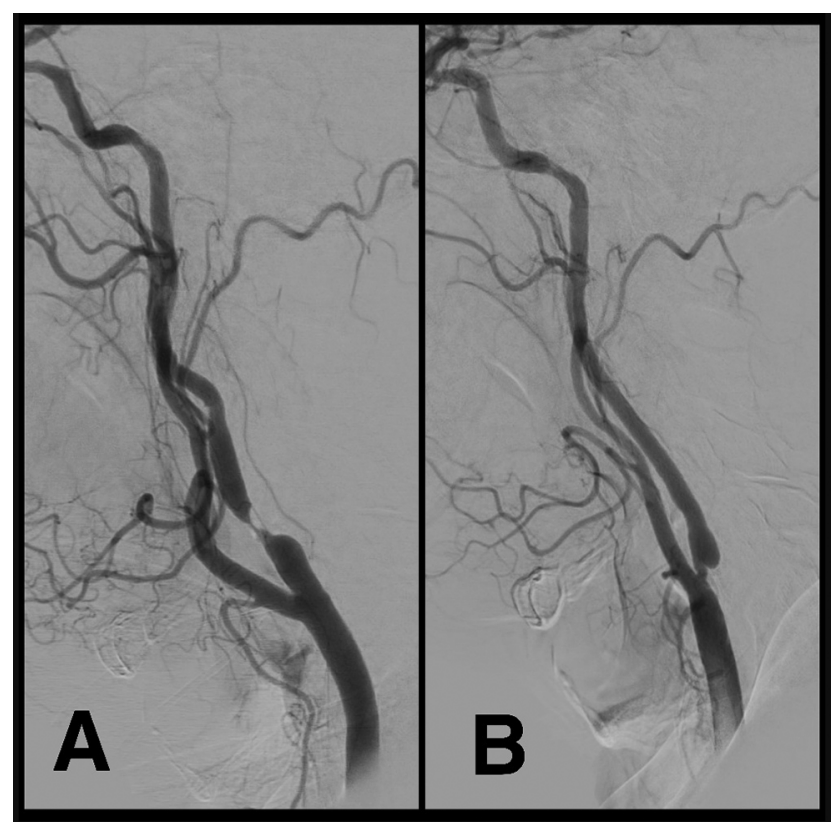

Fig.1 (A) Digital subtraction angiography of the left carotid artery demonstrating more than $90 \%$ stenosis of the internal carotid artery (symptomatic). (B) Around $80 \%$ stenosis seen in the right internal carotid artery.

the next 45 minutes and corresponded with the complete neurological recovery.

The noninvasive nature and continuous real-time interpretation make NIRS an attractive adjunct in the neuroanesthesiolgist's armamentarium for monitoring cerebral ischemia. However, significant contribution from chromophores in the extra-cerebral tissues and external carotid artery circulation can limit its sensitivity during occlusion of the internal carotid artery. ${ }^{4}$ In our case, it did not reflect brain ischemia during hypotension and when the neurological symptoms were obvious. The ST segment depression and hypotension, probably secondary to sudden cerebral ischemia and myocardial dysfunction, confused the clinical picture. ${ }^{5}$ The patient made neurological recovery after balloon deflation at a lower blood pressure than baseline, suggesting that the neurological symptoms were due to balloon occlusion causing total occlusion of the blood flow and not from a hemodynamic etiology. General anesthesia, if adopted, for conduct of carotid artery stenting, which the interventional radiologist requested for as this patient became restless, would have masked the occlusion intolerance and resulted in a periprocedural stroke. The sensitivity of cerebral oximetry has been reported to be modest when compared with awake testing. ${ }^{6}$ Commonly available cerebral oximetry sensors placed over the frontal region do not cover the parietal lobe where ischemia is likely to occur during occlusion of the carotid artery. ${ }^{7}$ In such scenarios, it has been shown that multichannel NIRS has a better sensitivity in detecting cerebral ischemia. ${ }^{8}$

This case report highlights the importance of frequent neurological examination during carotid stenting as $\mathrm{rSO} 2$ values might not always suggest cerebral ischemia.

We would like to thank Dr. Shamick Biswas and Dr. Shahyan Siddiqui, interventional radiologists, for their help with interpretation of the angiography findings.

\section{Acknowledgments}

We would like to thank Dr. Shamick Biswas and Dr. Shahyan Siddiqui, interventional radiologists, for their help with interpretation of the angiography findings.

\section{Conflict of Interest}

None declared.

\section{References}

1 Omran J, Mahmud E, White CJ, et al. Proximal balloon occlusion versus distal filter protection in carotid artery stenting: A meta-analysis and review of the literature. Catheter Cardiovasc Interv 2017;89(5):923-931

2 Giugliano G, Stabile E, Biamino G, et al. Predictors of carotid occlusion intolerance during proximal protected carotid artery stenting. JACC Cardiovasc Interv 2014;7(11):1237-1244

3 Kakumoto K, Harada K, Sankoda Y, Taniguchi S, Fukuyama K. Near-infrared spectroscopy cerebral oximetry as a predictor of neurological intolerance during carotid artery stenting with proximal protection. J Clin Neurosci 2018;58:89-93

4 Lam JM, Smielewski P, al-Rawi P. Griffiths P, Pickard JD, Kirkpatrick PJ. Internal and external carotid contributions to near-infrared spectroscopy during carotid endarterectomy. Stroke 1997;28(5):906-911

5 McDermott MM, Lefevre F, Arron M, Martin GJ, Biller J. ST segment depression detected by continuous electrocardiography in patients with acute ischemic stroke or transient ischemic attack. Stroke 1994;25(9):1820-1824

6 Stilo F, Spinelli F, Martelli E, et al. The sensibility and specificity of cerebral oximetry, measured by INVOS - 4100, in patients undergoing carotid endarterectomy compared with awake testing. Minerva Anestesiol 2012;78(10):1126-1135

7 Samra SK, Dy EA, Welch K, Dorje P, Zelenock GB, Stanley JC. Evaluation of a cerebral oximeter as a monitor of cerebral ischemia during carotid endarterectomy. Anesthesiology 2000;93(4):964-970

8 Rummel C, Zubler C, Schroth G, et al. Monitoring cerebral oxygenation during balloon occlusion with multichannel NIRS. J Cereb Blood Flow Metab 2014;34(2):347-356 